\title{
Synthesis of a Tetraepoxy Nanobelt and Its Reductive Aromatization Attempts
}

\author{
Yi Han' \\ Shaoqiang Dong ${ }^{a}$ \\ Yuan Cheng Liau ${ }^{\mathrm{a}}$ \\ Chunyan Chi*a (iD) \\ ${ }^{a}$ Department of Chemistry, National University of Singapore, 3 Science Drive 3, \\ 117543, Singapore \\ chmcc@nus.edu.sg
}

Received: 13.09.2020

Accepted after revision: 09.10 .2020

DOI: 10.1055/s-0040-1721101; Art ID: om-20-0031sc

License terms: cc)

(c) 2020. The Author(s). This is an open access article published by Thieme under the terms of the Creative Commons Attribution-NonDerivative-NonCommercial-License, permitting copying and reproduction so long as the original work is given appropriate credit. Contents may not be used for commercial purposes, or adapted, remixed, transformed or built upon. (https://creativecommons.org/licenses/by-nc-nd/4.0/).

Abstract Hydrocarbon nanobelts have recently attracted tremendous interest. Herein, we report our recent progress towards the synthesis of a newly designed hydrocarbon nanobelt tetrabenzo[10]cyclacene, which can be regarded as a sidewall fragment of the $(10,0)$ carbon nanotube. The structures of both key intermediates - "U"-shape diepoxy building block and tetraepoxy nanobelt - were confirmed by single-crystal $X$-ray diffraction. Our preliminary reductive aromatization reactions revealed that a tetrahydrogenated species instead of tetrabenzo[10]cyclacene was formed during this process. Computational results further revealed that hydrogenation can lead to significant strain release of the backbone structure of tetrabenzo[10]cyclacene, which may attribute to the absence of the target compound during the reductive aromatization.

Key words hydrocarbon nanobelts, reductive aromatization, hydrogenation, strain

\section{Introduction}

Single-walled carbon nanotubes (SWCNTs) have attracted tremendous interest from scientists since they have intriguing physical properties ${ }^{1}$ and wide applications, such as flexible electronics and energy storage. ${ }^{2}$ However, current preparation methods of SWCNTs have limited capability to guarantee their exact structural uniformity. Successful atomically precise synthesis of SWCNTs is still restricted. Hydrocarbon nanobelts can be regarded as sidewall segments of SWCNTs. They can also serve as precursors for template synthesis of structurally uniform SWCNTs with defined

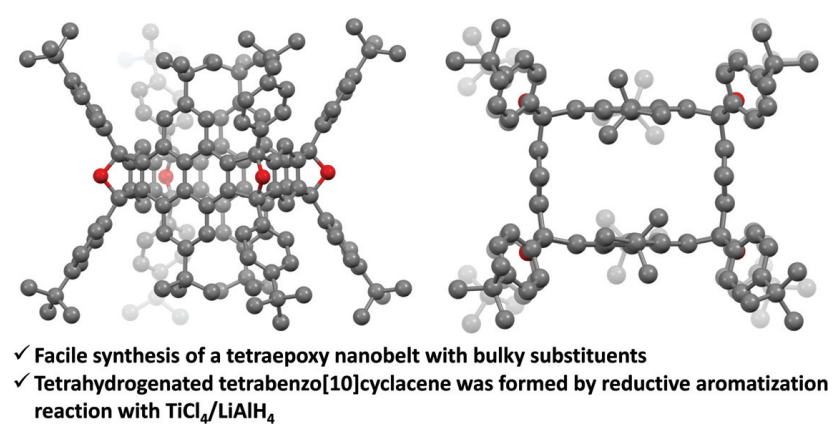

carbon architectures and diameters. ${ }^{3}$ They can be also used as model compounds to understand the fundamental properties of SWCNTs with different carbon architectures. ${ }^{4}$ Just like SWCNTs, architectures of hydrocarbon nanobelts can also be categorized into armchair, zigzag, and chiral nanobelts (Figure 1a) with regard to the chiral indices of the corresponding SWCNTs $(n, m) .^{5}$

With the development of chemistry toolbox and iterative efforts of synthetic chemists, the first armchair and chiral hydrocarbon nanobelts have been synthesized by Itami's ${ }^{6}$ and Miao's groups, ${ }^{7}$ respectively, in recent years (Figure 1b). However, the attempted syntheses of the zigzag hydrocarbon nanobelts have only met partial success. Pioneer synthesis of zigzag carbon nanobelts led by Stoddart, ${ }^{8}$ Cory $^{9}$, and Schlüter ${ }^{10}$ took advantage of repetitive Diels-Alder reactions on bisdiene and bisdienophile. Although the macrocyclic a)

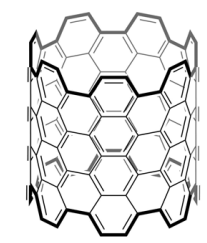

Armchair SWCNTs

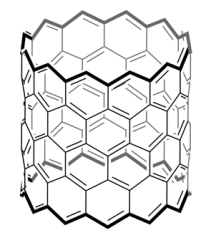

Zigzag SWCNTs b)

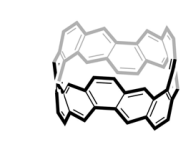

Itami's Armchair nanobelt

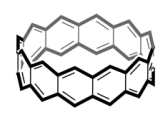

[12]cyclacene

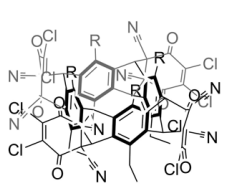

[8]cyclacene - DDQ adduct

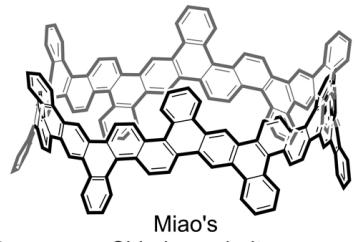

Chiral nanobelt

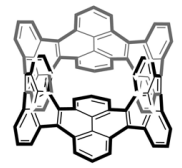

[12]benzo[12]cyclacene

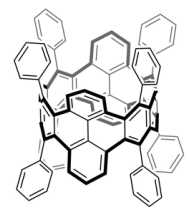

This work (proposed)
Figure 1 Representative structures of a) SWCNTs and b) recent progress towards hydrocarbon nanobelts. 
precursors were obtained successfully, the final aromatization step could not be fully accomplished due to the increasing intrinsic strain during the reaction process. More recently, Peña's group took advantage of the Diels-Alder reaction between benzynes and furans and tried to perform deoxygenative aromatization on surface to synthesize [8] and [10] cyclacenes. However, only partial deoxygenation was achieved. ${ }^{11}$ Wang's group recently tried to synthesize [8] cyclacene from resorcin[4]arenes, and so far only its adduct with four DDQs was fully characterized (Figure 1b). ${ }^{12}$

The extremely challenging synthesis of $[n]$ cyclacenes originates from their high strain and poor stability. The closed-shell resonance form of $[n]$ cyclacene contains only a diene-type conjugation without any aromatic sextet ring. ${ }^{13}$ According to Clar's rule, such structure is predicted to be unstable. Furthermore, computational studies revealed that $[n]$ cyclacene has an open-shell singlet ground state, which further demonstrates its high reactivity. ${ }^{14}$ Annulation of benzene rings on the zigzag edge of $[n]$ cyclacene is supposed to stabilize the whole structure. ${ }^{15}$ In 2016, Itami's group proposed the synthesis of $[n]$ benzo[ $n]$ cyclacenes (Figure 1b). However, rearrangement occurred at the final step and the target structure was not obtained. ${ }^{15}$ Recently, Miao's group proposed the synthetic routes towards $\mathrm{N}$-doped zigzag carbon nanobelt and tetrabenzo[10]cyclacene. ${ }^{16}$ Although the precursors were successfully obtained and characterized, the hydrogenated molecules instead of target structures were formed in the last step. Another recent work on carbon nanobelts with partial zigzag edges was reported as a preprint by Itami and co-workers. ${ }^{17}$

According to our experience towards the synthesis of long acenes, we believe that both benzo-annulation and attachment of kinetic protecting groups are the key strategies to stabilize cyclacene-like structures. We found that pyreno

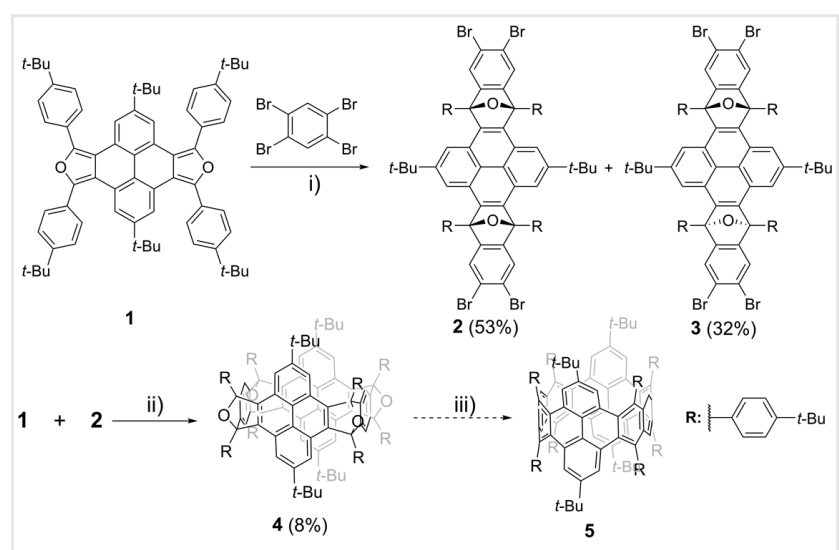

Scheme 1 Synthetic route towards tetraepoxy nanobelt 4 and tetrabenzo[10]cyclacene 5 . (i) $n$-BuLi, $-15^{\circ} \mathrm{C} \rightarrow \mathrm{rt}$, toluene, $1,2,4,5$ tetrabromobenzene, overnight; (ii) $n$-BuLi, $-15^{\circ} \mathrm{C} \rightarrow \mathrm{rt}$, toluene, overnight; (iii) reductive deoxygenation (various conditions were attempted, and are shown in Table 1). [4,5-c:9,10-c']difuran reported by Mastalerz's and Zhang's groups ${ }^{18}$ can serve as a good building block for the synthesis of hydrocarbon nanobelts for the following reasons. First, it can provide benzo-annulated cyclacene backbones which would introduce more Clar's sextets as compared to parent cyclacenes. Second, it can provide extra kinetic protections by attaching bulky groups. The solubility of this building block and the final compound will be improved as well. To push forward the limit of synthetic hydrocarbon nanobelts from the aspects of both strain and stability, ${ }^{19}$ the synthetic route towards tetrabenzo[10]cyclacene was thus designed as shown in Scheme 1. Herein, we report the synthesis of the crucial intermediate-the tetraepoxy hydrocarbon cage 4-and preliminary deoxygenation results, as well as strain analysis towards tetrabenzo[10]cyclacene $\mathbf{5}$.

\section{Results and Discussion}

The synthetic route of tetraepoxy nanobelt $\mathbf{4}$ and tetrabenzo[10]cyclacene $\mathbf{5}$ is shown in Scheme 1. Synthesis of the key precursor $\mathbf{1}$ is generally followed Mastalerz's report ${ }^{18 \mathrm{a}}$ with an improved procedure. Compound 1 exhibits moderate stability in silica gel column but poor solubility in dichloromethane (DCM) and hexane, which makes purification difficult by column chromatography. Luckily, compound 1 could be purified by washing with ether. Benzyne was generated from 1,2,4,5-tetrabromobenzene in situ through a lithium-halogen exchange reaction and an elimination reaction at $-15{ }^{\circ} \mathrm{C}$ in toluene. ${ }^{20}$ Compound 1 then reacts with benzyne overnight to give the cis-isomer 2 and the transisomer 3 with $53 \%$ and $32 \%$ yield, respectively. ${ }^{21}$ The structure of the cis-isomer $\mathbf{2}$ was confirmed by single-crystal X-ray diffraction (XRD) ${ }^{22}$ It showed larger polarity than the transisomer 3 on TLC. Dibenzyne was then generated from the cisisomer $\mathbf{2}$ and reacted with compound $\mathbf{1}$ to form the tetraepoxy nanobelt 4 with $8 \%$ yield. ${ }^{23}$ The structure of 4 was also confirmed by single-crystal XRD. ${ }^{24}$ Reductive deoxygenation of 4 was attempted by using various conditions, which will be discussed later.

Single crystals of $\mathbf{2}$ suitable for X-ray analysis were obtained by vapor diffusion of methanol into its chloroform solution. The crystal structure of $\mathbf{2}$ is shown in Figure $2(\mathrm{a}, \mathrm{b})$. Due to the oxygen bridge, the backbone of $\mathbf{2}$ has a "U"-shaped conformation. The dihedral angle $\theta$ between the terminal dibrominated phenyl rings and the central pyrene unit is $87^{\circ}$, which is smaller than that of disubstituted 9,10-epoxyanthracene counterpart. ${ }^{25}$ Such a dihedral angle indicates that the formation of 4 , instead of other nanobelts with larger size, was favored. Bond angles $\alpha$ and $\beta$ of the $\mathrm{sp}^{3}$ carbon are $102^{\circ}$ and $121^{\circ}$, respectively [Figure S4 in the Supporting Information (SI)]. The $\beta$ angle is largely deviated from the normal $\mathrm{sp}^{3}$ bond angle $109^{\circ}$ due to steric hindrance between the substituted tert-butyl phenyl rings and the central tert-butyl pyrene unit. 
a)

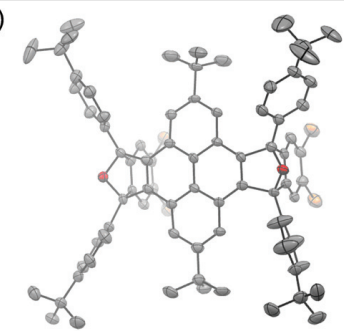

c)

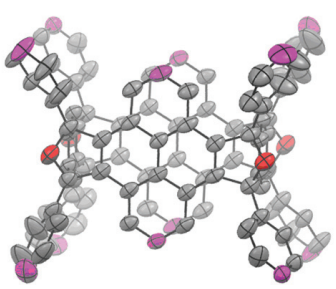

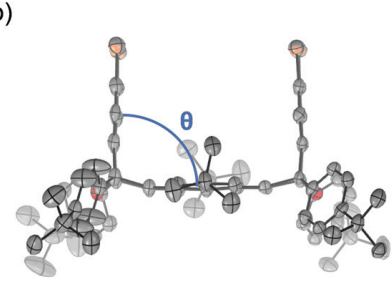

d)

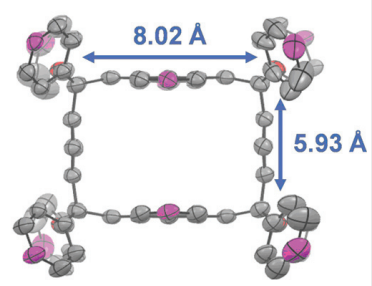

Figure 2 Single crystal structures of $\mathbf{2}$ (a: side view, b: top view) and $\mathbf{4}$ (c: side view, d: top view) drawn as ellipsoids set at $50 \%$ probability. Hydrogen atoms are all omitted for clarity. The $t$-butyl groups of $\mathbf{4}$ are omitted for clarity and the attached sites are highlighted in pink.

Single crystals of $\mathbf{4}$ suitable for X-ray analysis were obtained by vapor diffusion of methanol into its THF solution. The crystal structure of $\mathbf{4}$ is shown in Figure 2 (c, d). The backbone of tetraepoxy nanobelt 4 is shaped like a small box, which is $8.02 \AA$ long and $5.93 \AA$ wide. The cavity of this box, however, may be too small to host some guest molecules for supramolecular chemistry studies. The packing of 4 was very loose due to the cyclic geometry as shown in Figure 3. No $\pi-\pi$ interactions were observed between the neighboring molecules of 4.

The electrochemical and optoelectronic properties of compound $\mathbf{4}$ were subsequently characterized and are shown in Figure 4 . The cyclic voltammogram of $\mathbf{4}$ in DCM showed two reversible oxidation waves with a half-wave potential $\left(E_{1 / 2}{ }^{\text {ox }}\right)$ at 0.71 and $1.06 \mathrm{~V}$, respectively (vs. $\mathrm{Fc}^{+} / \mathrm{Fc}$ ) (Figure 4a). However, no reduction wave was observed in the testing window. In DCM, compound 4 has a long-wavelength absorption maximum at $407 \mathrm{~nm}$ (Figure 4b). This absorption band is attributed to the $S_{0}-S_{1}$ transition as revealed by TDDFT calculations (oscillator strength $f=0.1308$ ). The band gap estimated from onset of low-energy edge of the absorption spectrum is $2.93 \mathrm{eV}$, which is in accordance with the computational result $3.13 \mathrm{eV}$ (see also Figure S2 in $\mathrm{SI})$. Compound $\mathbf{4}$ emits blue fluorescence with an emission maximum at $420 \mathrm{~nm}$. The absolute external fluorescence quantum yield was measured to be $8.99 \%$ by using an integrating sphere.

Inspired by the successful synthesis of tetraepoxy nanobelt 4 , we proceeded to do the final step of reductive aromatization, which is not a trivial reaction. ${ }^{26}$ Several conditions were examined as shown in Table 1. We first tried reaction conditions 1 and 2 which are often used for

a)

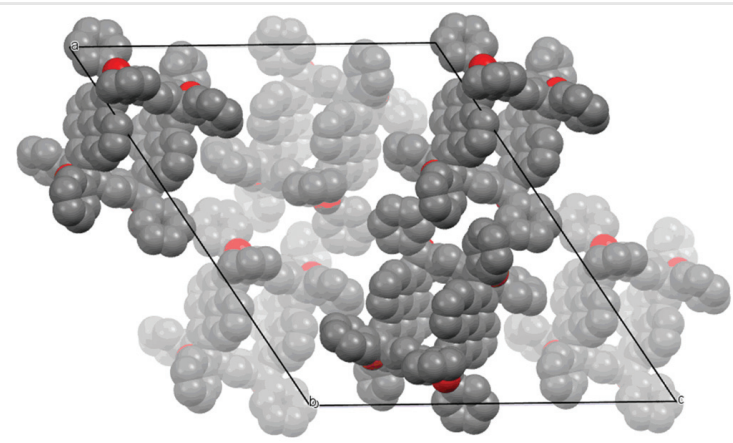

b)

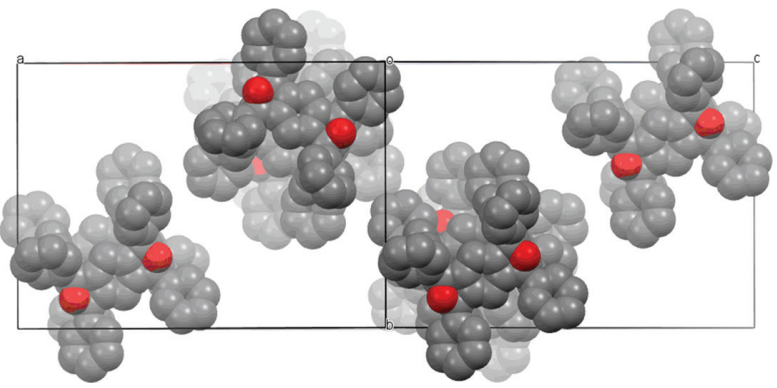

Figure 3 (a, b) Packing structure of $\mathbf{4}$ shown in space filling mode, hydrogens and $t$-butyl groups are omitted for clarity.

a)

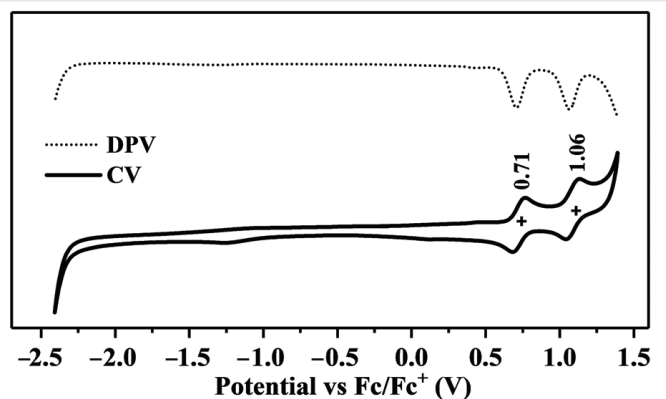

b)

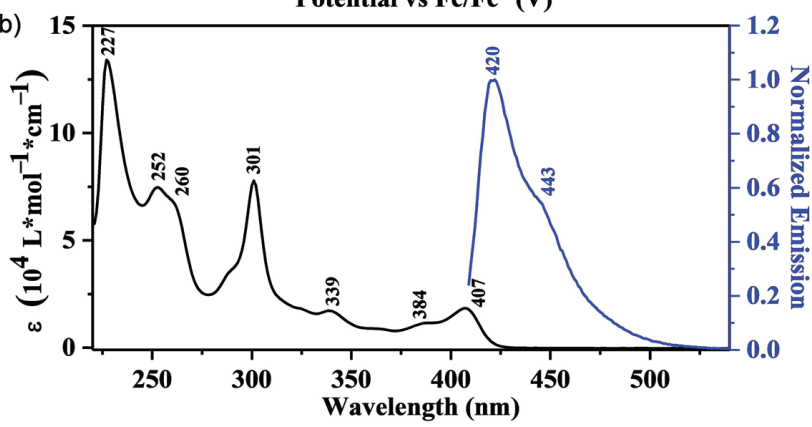

Figure 4 (a) Cyclic voltammograms and differential pulse voltammetry of $\mathbf{4}$ in $\mathrm{DCM}$ with $\mathrm{Bu}_{4} \mathrm{NPF}_{6}$ as the electrolyte; scanning rate is $0.1 \mathrm{~V} / \mathrm{s}$. (b) UV-vis absorption and fluorescence spectra of $\mathbf{4}$ in DCM.

the preparation of acenes. ${ }^{27}$ However, the reaction did not take place since no new spot was observed on TLC and $\mathbf{4}$ remained unchanged. To avoid harsh conditions, we then tried reaction conditions 3 and $4 .^{28}$ Although deoxygenation 
Table 1 Examined reductive aromatization conditions towards 5

\begin{tabular}{|c|c|c|}
\hline No. & Reaction conditions & $\begin{array}{l}\text { Products detected by } \\
\text { MALDI-TOF MS }\end{array}$ \\
\hline 1 & $\mathrm{Zn}, 10 \% \mathrm{AcOH}$ in toluene, reflux & No reaction \\
\hline 2 & $\mathrm{TiCl}_{4}, \mathrm{Zn}$, toluene, reflux & No reaction \\
\hline 3 & $\mathrm{TFA}, \mathrm{Et}_{3} \mathrm{SiH}, \mathrm{CHCl}_{3}, \mathrm{rt}$ & Various hydrogenated products \\
\hline 4 & TFA, 1,4-cyclohexadiene, $\mathrm{CHCl}_{3}$, rt & Various hydrogenated products \\
\hline 5 & $\mathrm{TiCl}_{3} \cdot \mathrm{AlCl}_{3} / n-\mathrm{BuLi}, \mathrm{THF}, 0{ }^{\circ} \mathrm{C}$ to rt & {$[4-0]$ and $[4-20]$} \\
\hline 6 & $\mathrm{TiCl}_{4} / \mathrm{LAH} 9: 5, \mathrm{Et}_{3} \mathrm{~N}$, THF, reflux & {$[4-0]$ and $[4-20]$} \\
\hline 7 & $\mathrm{TiCl}_{4} / \mathrm{LAH} 3: 8, \mathrm{Et}_{3} \mathrm{~N}$, THF, reflux & {$[4-30]$} \\
\hline 8 & $\mathrm{TiCl}_{4} / \mathrm{LAH} 3: 16, \mathrm{Et}_{3} \mathrm{~N}$, THF, reflux & {$[5+4 \mathrm{H}]$} \\
\hline
\end{tabular}

occurred, various hydrogenated products were observed, which was probably due to side reactions of deoxygenated intermediates with protonic acid. Condition 5 was subsequently attempted, which was proved to be effective for the reduction towards another strained system-twistacenes. ${ }^{29}$ However, the deoxygenation was not complete for our system, even with a large excess amount of reductants. At the edge of surrender, we turned to the classical combination of $\mathrm{TiCl}_{4} / \mathrm{LiAlH}_{4}(\mathrm{LAH})$, which is widely applied in the reduction of unstrained endoxides as well as Mcmurry couplings. ${ }^{30}$ Unexpectedly, we found that deoxygenation's progress could be promoted by decreasing the ratio of $\mathrm{TiCl}_{4} /$ LAH as seen under conditions $6-8$. Although the final compound $\mathbf{5}$ was not observed on the MALDI-TOF mass spectrum, its tetrahydrogenated compound 6 was observed (Figure $5 c$ ). However, the low yield of the final step and purification issues hindered further characterization of compound 6.

The absence of target compound $\mathbf{5}$ upon reductive aromatization can be attributed to its high intrinsic strain. The electronic structure of the backbone of 5 was calculated [B3LYP/6-31G(d,p)], which exhibits a close-shell ground state with a large band gap. Such electronic properties indicate that the backbone of $\mathbf{5}$ should be much more stable than the [10]cyclacene counterpart. Meanwhile, the strain of [10]cyclacene calculated from a hypothetical homodesmotic reaction was estimated to be $132 \mathrm{kcal} / \mathrm{mol}$ according to a previous report. ${ }^{31}$ The strain of the backbone of $\mathbf{5}$, as shown in Figure 6a, was estimated to be $136 \mathrm{kcal} / \mathrm{mol}$, which is similar to that of [10]cyclacene. Such strain is much larger than that of any reported hydrocarbon nanobelt. We then calculated the intrinsic strain of dihydrogenated and tetrahydrogenated compounds of $\mathbf{5}$, which are shown in Figure 6 (b, c). It revealed that dihydrogenation of $\mathbf{5}$ would release $43 \mathrm{kcal} / \mathrm{mol}$ of the intrinsic strain, so the strain of the dihydrogenated compound is about $93 \mathrm{kcal} / \mathrm{mol}$. The strain of the tetrahydrogenated species was calculated to be 43 $\mathrm{kcal} / \mathrm{mol}$, which is $50 \mathrm{kcal} / \mathrm{mol}$ less than that of the dihydrogenated species. Such a strain release process
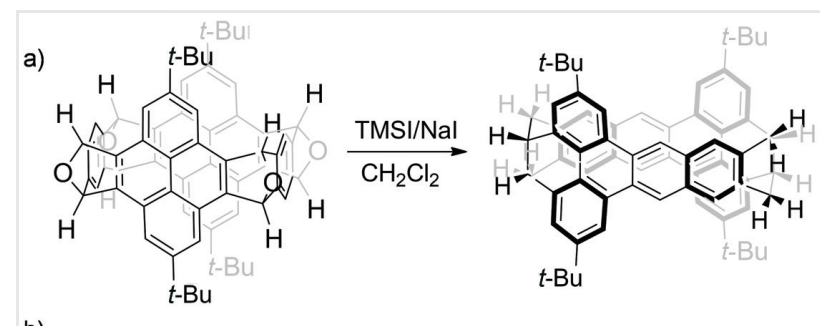

b)

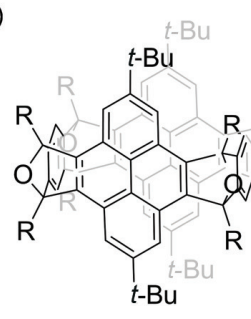

5

c)
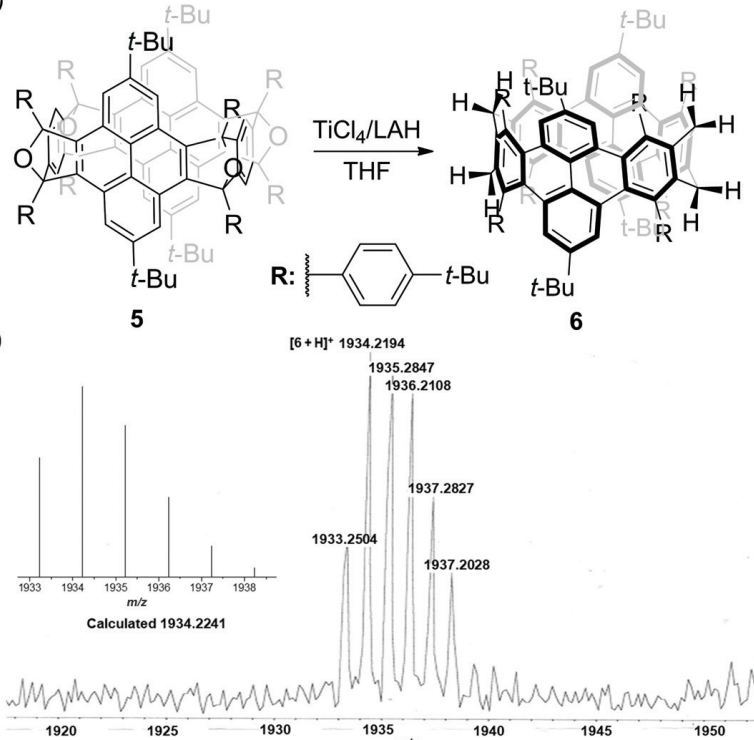

$\left[6+\mathrm{H}^{+}+1934.2194\right.$

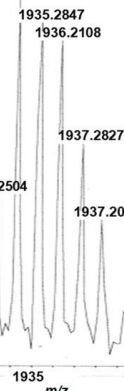

${ }^{1935}$

1940

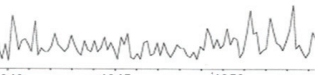

Figure 5 Different reductive products during attempts towards the synthesis of tetrabenzo[10]cyclacene, (a) Miao's report ${ }^{16 \mathrm{~b}}$ and (b) possible reaction and structure of $\mathbf{6}$ in this work, aromatic sextet rings are highlighted in bold. (c) High-resolution MALDI-TOF mass spectrum of 6. a)

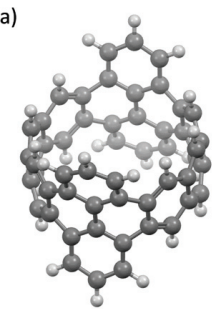

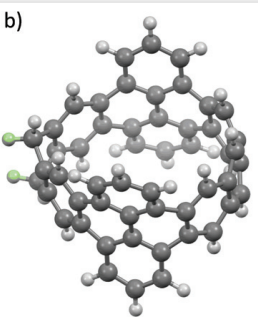

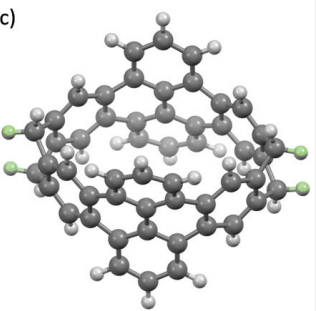

Figure 6 Molecular geometries optimized by DFT calculations (a) proposed nanobelt $\mathbf{5}$ without substituted phenyl groups, (b) dihydrogenated form of $\mathbf{5}$, (c) compound $\mathbf{6}$ without substituted phenyl groups. The added hydrogens are highlighted with light green.

indicates that hydrogenation may happen easily during the reductive aromatization process and possibly explains the absence of compound $\mathbf{5}$ as the final product.

Interestingly, we noticed that our attempts at reductive aromatization reactions gave the product that differs from that in Miao's report. ${ }^{16 b}$ As shown in Figure $5 \mathrm{a}$, a total of eight hydrogens were added to the backbone of tetrabenzo[10]cyclacene in Miao's work. The result was explained by the instability of the belt compound during 
reductive aromatization due to the accumulating strain. However, in our case, only tetrahydrogenated compound 6 was observed in the MALDI-TOF mass spectrum (Figure 5c). As shown in Figure 5b, tetrahydrogenation most likely happened in the central benzene units since they are unprotected and are considered to be the most reactive sites according to Clar's rule. Our results indicate that attachment of proper protective groups along the backbone and reduction by the combination of $\mathrm{TiCl}_{4} / \mathrm{LAH}$ may be promising strategies in the construction of hydrocarbon nanobelts with partial zigzag edges.

\section{Conclusions}

In summary, we reported our recent progress towards the synthesis of sidewall fragments of the $(10,0)$ carbon nanotube. The structures of the precursor 2 and tetraepoxy belt 4 were unambiguously confirmed by single-crystal XRD. The preliminary results on reductive aromatization reactions revealed that $\mathrm{TiCl}_{4} / \mathrm{LAH}$ in a lower ratio may be promising reductants for aromatization of epoxy-containing molecules with high strain. The tetrahydrogenated compound $\mathbf{6}$ was observed in the MALDI TOF mass spectrum during the reduction process. Our computational results revealed that the backbone of tetrabenzo[10]cyclacene is highly strained and hydrogenation can greatly release its strain. Thus, hydrogenation may happen easily during the reductive aromatization process and lead to the absence of $\mathbf{5}$ as the final product. Our results indicate that the combination of proper protective groups and reduction by $\mathrm{TiCl}_{4} / \mathrm{LAH}$ may be the promising strategies in the construction of strained hydrocarbon nanobelts. We hope our results can provide valuable information towards the rational design and synthesis of hydrocarbon nanobelts with partial zigzag edges.

\section{Funding Information}

We acknowledge financial support from the MOE Tier 1 grant (R-143-000-B62-114) and Tier 2 grant (MOE2018-T21-152).

\section{Acknowledgment}

We thank Dr. Tan Geok Kheng for the guidance on crystallographic analysis.

\section{Supporting Information}

Supporting Information for this article is available online at http://doi.org/10.1055/s-0040-1721101.

\section{References And Notes}

(1) (a) Tasis, D.; Tagmatarchis, N.; Bianco, A.; Prato, M. Chem. Rev. 2006, 106, 1105. (b) Dai, H. Acc. Chem. Res. 2002, 35, 1035. (c) Fennimore, A. M.; Yuzvinsky, T. D.; Han, W. Q.; Fuhrer, M. S.; Cumings, J.; Zettl, A. Nature 2003, 424, 408. (d) Cumings, J.; Zettl, A. Science 2000, 289, 602.

(2) (a) Yang, Z.; Ren, J.; Zhang, Z.; Chen, X.; Guan, G.; Qiu, L.; Zhang, Y.; Peng, H. Chem. Rev. 2015, 115, 5159. (b) Sun, H.; Zhang, Y.; Zhang, J.; Sun, X.; Peng, H. Nat. Rev. Mater. 2017, 2, 1.

(3) (a) Omachi, H.; Nakayama, T.; Takahashi, E.; Segawa, Y.; Itami, K. Nat. Chem. 2013, 5, 572. (b) Sanchez-Valencia, J. R.; Dienel, T.; Gröning, O.; Shorubalko, I.; Mueller, A.; Jansen, M.; Amsharov, K.; Ruffieux, P.; Fasel, R. Nature 2014, 512, 61.

(4) (a) Nishiuchi, T.; Feng, X.; Enkelmann, V.; Wagner, M.; Müllen, K. Chem. Eur. J. 2012, 18, 16621. (b) Quernheim, M.; Golling, F. E.; Zhang, W.; Wagner, M.; Räder, H. J.; Nishiuchi, T.; Müllen, K. Angew. Chem. Int. Ed. 2015, 54, 10341. (c) Lu, D.; Zhuang, G.; Wu, H.; Wang, S.; Yang, S.; Du, P. Angew. Chem. Int. Ed. 2017, 56, 158. (d) Huang, Q.; Zhuang, G.; Zhang, M.; Wang, J.; Wang, S.; Wu, Y.; Yang, S.; Du, P.J. Am. Chem. Soc. 2019, 141, 18938. (e) Hitosugi, S.; Nakanishi, W.; Yamasaki, T.; Isobe, H. Nat. Commun. 2011, 2, 492. (f) Sun, Z.; Ikemoto, K.; Fukunaga, T. M.; Koretsune, T.; Arita, R.; Sato, S.; Isobe, H. Science 2019, 363, 151. (g) Sisto, T. J.; Zakharov, L. N.; White, B. M.; Jasti, R. Chem. Sci. 2016, 7, 3681.

(5) Saito, R.; Fujita, M.; Dresselhaus, G.; Dresselhaus, M. S. Appl. Phys. Lett. 1992, 60, 2204.

(6) (a) Povie, G.; Segawa, Y.; Nishihara, T.; Miyauchi, Y.; Itami, K. Science 2017, 356, 172. (b) Povie, G.; Segawa, Y.; Nishihara, T.; Miyauchi, Y.; Itami, K. J. Am. Chem. Soc. 2018, 140, 10054.

(7) Cheung, K. Y.; Gui, S.; Deng, C.; Liang, H.; Xia, Z.; Liu, Z.; Chi, L.; Miao, Q. Chem 2019, 5, 838.

(8) (a) Kohnke, F. H.; Slawin, A. M. Z.; Stoddart, J. F.; Williams, D. J. Angew. Chem. Int. Ed. Engl. 1987, 26, 892. (b) Aston, P. R.; Isaacs, N. S.; Kohnke, F. H.; Slawin, A. M. Z.; Spencer, C. M.; Stoddart, J. F.; Williams, D. J. Angew. Chem. Int. Ed. Engl. 1988, 27, 966.

(9) (a) Cory, R. M.; Mcphail, C. L.; Dikmans, A. J.; Vittal, J. J. Tetrahedron Lett. 1996, 37, 1983. (b) Cory, R. M.; Mcphail, C. L. Tetrahedron Lett. 1996, 37, 1987.

(10) (a) Neudorff, W. D.; Lentz, D.; Anibarro, M.; Schlüter, A. D. Chem. Eur. J. 2003, 9, 2745. (b) Stuparu, M.; Lentz, D.; Rüegger, H.; Schlüter, A. D. Eur. J. Org. Chem. 2007, 2007, 88.

(11) Schulz, F.; García, F.; Kaiser, K.; Pérez, D.; Guitián, E.; Gross, L.; Peña, D. Angew. Chem. Int. Ed. 2019, 58, 9038.

(12) (a) Shi, T. H.; Guo, Q. H.; Tong, S.; Wang, M. X. J. Am. Chem. Soc. 2020, 142, 4576. (b) Wang, M.; Shi, T.; Tong, S. Angew. Chem. Int. Ed. 2020. Doi: 10.1002/anie.202002827. (c) Zhang, Q.; Zhang, Y. E.; Tong, S.; Wang, M. X. J. Am. Chem. Soc. 2020, 142, 1196.

(13) Clar, E. The Aromatic Sextet. J. Wiley: London, 1972.

(14) (a) Choi, H. S.; Kim, K. S. Angew. Chem. Int. Ed. 1999, 38, 2256. (b) Chen, Z.; Jiang, D. E.; Lu, X.; Bettinger, H. F.; Dai, S.; Schleyer, Pv.; Houk, K. N. Org. Lett. 2007, 9, 5449.

(15) Matsui, K.; Fushimi, M.; Segawa, Y.; Itami, K. Org. Lett. 2016, 18, 5352.

(16) (a) Wang, J.; Miao, Q. Org. Lett. 2019, 21, 10120. (b) Chen, H.; Gui, S.; Zhang, Y.; Liu, Z.; Miao, Q. CCS Chem. 2020, 2, 613.

(17) Cheung, K. Y.; Watanabe, K.; Segawa, Y.; Itami, K. ChemRxiv 2020. Doi: 10.26434/chemrxiv.12324353.v2.

(18) (a) Baumgärtner, K.; Kirschbaum, T.; Krutzek, F.; Dreuw, A.; Rominger, F.; Mastalerz, M. Chem. Eur. J. 2017, 23, 17817. (b) Chen, W.; Long, G.; Kanehira, K.; Zhang, M.; Michinobu, T.; Liu, M.; Zhang, Q. Asian J. Org. Chem. 2018, 7, 2213. 
(19) (a) Eisenberg, D.; Shenhar, R.; Rabinovitz, M. Chem. Soc. Rev. 2010, 39, 2879. (b) Segawa, Y.; Yagi, A.; Matsui, K.; Itami, K. Angew. Chem. Int. Ed. 2016, 55, 5136. (c) Lu, X.; Wu, J. Chem 2017, 2, 619. (d) Majewski, M. A.; Stępień, M. Angew. Chem. Int. Ed. 2018, 58, 86.

(20) (a) Haneda, H.; Eda, S.; Aratani, M.; Hamura, T. Org. Lett. 2014, 16, 286. (b) Eda, S.; Hamura, T. Molecules 2015, 20, 19449.

(21) Synthetic procedure for compounds 2 and 3: Compound 1 (923 $\mathrm{mg}, 1 \mathrm{mmol}$ ) and 1,2,4,5-tetrabromobenzene (7.8 g, $20 \mathrm{mmol}$ ) were dissolved in $400 \mathrm{~mL}$ anhydrous toluene and cooled to $-15{ }^{\circ} \mathrm{C}$. $n$-BuLi ( $2 \mathrm{M}$ in hexane, $5 \mathrm{~mL}, 10 \mathrm{mmol}$ ) was added dropwise into the reaction mixture. The reaction mixture was then warmed up to room temperature overnight. Saturated $\mathrm{NH}_{4} \mathrm{Cl}$ solution was used to quench the reaction. The solution was further washed with water and the organic layer was dried over $\mathrm{Na}_{2} \mathrm{SO}_{4}$. The residue was purified via column chromatography (silica, hexane:DCM, 1:1 v/v) to yield 2 (723 $\mathrm{mg}, 52 \%$ ) and 3 (445 mg, 32\%) as white solids. Compound 2: ${ }^{1} \mathrm{H}$ NMR $(400 \mathrm{MHz}$, chloroform- $d$ ): $\delta=7.95(\mathrm{~d}, J=8.0 \mathrm{~Hz}, 8 \mathrm{H}), 7.80(\mathrm{~s}, 4 \mathrm{H}), 7.73(\mathrm{~s}$, $4 \mathrm{H}), 7.57(\mathrm{~d}, J=8.5 \mathrm{~Hz}, 8 \mathrm{H}), 1.38(\mathrm{~s}, 36 \mathrm{H}), 0.99(\mathrm{~s}, 18 \mathrm{H}) .{ }^{13} \mathrm{C}$ NMR (126 MHz, chloroform-d): $\delta=152.93,152.74,148.89$, 147.93, 131.12, 129.85, 126.78, 126.35, 125.91, 122.58, 121.29, 119.39, 92.67, 35.05, 34.94, 31.40, 31.24. HRMS analysis (APCI) calcd. for $\mathrm{C}_{80} \mathrm{H}_{79} \mathrm{Br}_{4} \mathrm{O}_{2}(\mathrm{M}+\mathrm{H})^{+}$: 1387.2808 ; found: 1387.2803 (error: $0.4 \mathrm{ppm})$. Compound 3: ${ }^{1} \mathrm{H}$ NMR $(400 \mathrm{MHz}$, chloroformd): $\delta=7.92$ (br, $12 \mathrm{H}), 7.77(\mathrm{~s}, 4 \mathrm{H}), 7.55(\mathrm{~d}, J=8.4 \mathrm{~Hz}, 8 \mathrm{H}), 1.36$ $(\mathrm{s}, 36 \mathrm{H}), 0.99(\mathrm{~s}, 18 \mathrm{H}) .{ }^{13} \mathrm{C}$ NMR $(126 \mathrm{MHz}$, chloroform-d): $\delta=152.94,152.84,148.56,148.04,131.47,127.00,125.94$, $125.89,122.45,121.32,119.53,92.53,35.09,34.93,31.39,31.24$. HRMS analysis (APCI) calculated for $\mathrm{C}_{80} \mathrm{H}_{79} \mathrm{Br}_{4} \mathrm{O}_{2}(\mathrm{M}+\mathrm{H})^{+}$: 1387.2808; found: 1387.2809 (error: $-0.1 \mathrm{ppm}$ ).

(22) X-ray crystallographic data for compound $\mathbf{2}$ were deposited in the Cambridge Crystallographic Data Centre (CCDC) with the number of 2020884.

(23) Synthetic procedure for compound 4: Compound 1 (507 mg, $0.55 \mathrm{mmol})$ and $2(850 \mathrm{mg}, 0.61 \mathrm{mmol})$ were dissolved in anhydrous toluene $(150 \mathrm{~mL})$ under an inert atmosphere and cooled to $-15{ }^{\circ} \mathrm{C}$. $n$-BuLi ( $2 \mathrm{M}$ in hexane, $1.5 \mathrm{~mL} 3 \mathrm{mmol}$ ) was added dropwise into the reaction mixture. The reaction mixture was then warmed up to room temperature overnight. Saturated $\mathrm{NH}_{4} \mathrm{Cl}$ solution was used to quench the reaction. The residue was purified via column chromatography (silica, hexane:DCM, 1:1 $\mathrm{v} / \mathrm{v}$ ) to yield compound $\mathbf{4}$ (70 $\mathrm{mg}, 52 \%$ ) as a white solid. ${ }^{1} \mathrm{H}$ NMR (400 MHz, chloroform-d): $\delta=8.00(\mathrm{br}, 16 \mathrm{H}), 7.59(\mathrm{br}, 20 \mathrm{H})$, 7.37 (s, $8 \mathrm{H}), 1.39$ (s, $72 \mathrm{H}), 0.72$ (s, $36 \mathrm{H}) .{ }^{13}$ C NMR (126 MHz, chloroform-d): $\delta=152.37,150.66,149.45,146.93,132.58$, 125.84, 125.67, 121.57, 118.02, 116.48, 93.27, 34.94, 34.63, 31.46, 31.21. HRMS analysis (APCI) calculated for $\mathrm{C}_{148} \mathrm{H}_{153} \mathrm{O}_{4}$ $(\mathrm{M}+\mathrm{H})^{+}$: 1994.1763; found: 1994.1768 (error: $\left.-0.2 \mathrm{ppm}\right)$.

(24) X-ray crystallographic data for compound $\mathbf{4}$ were deposited in the Cambridge Crystallographic Data Centre (CCDC) with the number of 2020888.

(25) Miyamoto, N.; Nakazawa, Y.; Nakamura, T.; Okano, K.; Sato, S.; Sun, Z.; Isobe, H.; Tokuyama, H. Synlett 2018, 29, 513.

(26) Marshall, J. L.; Lehnherr, D.; Lindner, B. D.; Tykwinski, R. R. ChemPlusChem 2017, 82, 967.

(27) (a) Chun, D.; Cheng, Y.; Wudl, F. Angew. Chem. Int. Ed. 2008, 47, 8380. (b) Dai, G.; Chang, J.; Zhang, W.; Bai, S.; Huang, K. W.; Xu, J.; Chi, C. Chem. Commun. 2015, 51, 503.

(28) Tokuyama, H.; Miyamoto, N.; Nakazawa, Y.; Nakamura, T.; Okano, K.; Sato, S.; Sun, Z.; Isobe, H. Synlett 2017, 29, 513.

(29) (a) Lu, J.; Ho, D. M.; Vogelaar, N. J.; Kraml, C. M.; Pascal, R. A. Jr J. Am. Chem. Soc. 2004, 126, 11168. (b) Lu, J.; Ho, D. M.; Vogelaar, N. J.; Kraml, C. M.; Bernhard, S.; Byrne, N.; Kim, L. R.; Pascal, R. A. Jr J. Am. Chem. Soc. 2006, 128, 17043. (c) Xiao, Y.; Mague, J. T.; Schmehl, R. H.; Haque, F. M.; Pascal, R. A. Angew. Chem. Int. Ed. 2019, 58, 2831.

(30) (a) Mcmurry, J. E.; Fleming, M. P. J. Org. Chem. 1975, 40, 2555. (b) Mcmurry, J. E.; Silvestri, M. G.; Fleming, M. P.; Hoz, T.; Grayston, M. W. J. Org. Chem. 1978, 43, 3249. (c) Hart, H.; Nwokogu, G. J. Org. Chem. 1981, 46, 1251. (d) Wong, H. N. C. Acc. Chem. Res. 1989, 22, 145.

(31) (a) Segawa, Y.; Yagi, A.; Ito, H.; Itami, K. Org. Lett. 2016, 18, 1430. (b) Minkin, V. I. Pure Appl. Chem. 1999, 71, 1919. (c) George, P.; Trachtman, M.; Bock, C. W.; Brett, A. M. Tetrahedron 1976, 32, 317. 